\title{
EL PROYECTO DE UNA ESPAÑA GRANDE Y REGIONAL DE FRANCESC CAMBÓ
}

Borja de Riquer

Universitat Autònoma de Barcelona

DOI: 10.17075/iftpc.2021.008 

La historia del proyecto regeneracionista y autonomista del líder catalanista Francesc Cambó es la historia de un gran fracaso político fruto de los errores propios, tanto estratégicos como tácticos, pero también de las enormes resistencias que despertó ${ }^{1}$. Antes de entrar en la explicación detallada de este proyecto, y de sus limitaciones, quizás sea conveniente advertir que cualquier semejanza con aspectos de la actual situación política española y catalana no es una pura coincidencia, sino el evidente resultado de contemplar que, en nuestro país, hay aún cuestiones pendientes desde hace, como mínimo, un siglo.

El proyecto reformador y regionalista de Cambó se elaboró gracias a una serie de estímulos exteriores, surgidos de la política internacional, pero sobre todo como consecuencia de la peculiar coyuntura española de los años 1915-1917. En el terreno internacional, es evidente la influencia de la Gran Guerra y de la posición neutral que España adoptó ante ella. Pero, también, no dejaban de tener una notable repercusión ideológica algunos importantes cambios políticos producidos entonces, como los de México y el de Portugal -en ambos casos, de 1910- y también la Revolución rusa de 1917.

Por otra parte, debe tenerse en cuenta que ello llevó al catalanismo conservador de la Lliga Regionalista a elaborar una propuesta política de reformas para el conjunto de España. La irrupción del catalanismo en la política española fue, sin duda, la única gran novedad surgida tras el desastre colonial de 1898, pero

\footnotetext{
1 He tratado algunos aspectos importantes de esta temática en Alfonso XIII y Cambó: la monarquía y el catalanismo politico, Barcelona, RBA, 2013, y en Escolta, Espanya: la cuestión catalana en la época liberal, Madrid, Marcial Pons, Ediciones de Historia, 2001. También ha sido muy útil para este texto la consulta del artículo de Ángel Smith (2017) «Cataluña y la Gran Guerra: de la reforma democrática al conflicto social», Hispania Nova, 15, 472-499.
} 
no dejó de producir reacciones notablemente contradictorias. La presencia de los primeros diputados y senadores catalanistas, a partir del año 1901, acabó generando una amplia discusión política sobre la necesidad de una reforma de la Administración española de carácter descentralizador. Fue lo que Javier Tusell denominó hace años la «catalanización de los debates sobre la reforma del Estado» ${ }^{2}$. En efecto, ya desde 1901 los primeros diputados catalanistas, como el mismo doctor Bartomeu Robert, plantearon en el Congreso propuestas de carácter regeneracionista para el conjunto español, pero siempre aparecían como elaboradas desde Cataluña. Estas propuestas provocaron bien pronto no pocas suspicacias y bastantes reticencias entre los políticos de los partidos dinásticos. Más de uno de estos sostuvo en el propio Congreso que tras ellas había una clara pretensión catalana de modificar no solo el sistema del turno político del régimen de la Restauración, sino también el propio modelo económico.

Así, desde un primer momento la intención catalana de influir más en el mundo político y económico español fue vista como desequilibrante y peligrosa para el modelo de pactos tácitos establecidos desde los inicios de la Restauración, ya que además podía despertar a los otros regionalismos y estimularlos a seguir el mismo camino. Por ello, las propuestas regeneracionistas catalanas activarán el discurso del nacionalismo español más uniformista, que verá en todo planteamiento autonomista un grave peligro para la unidad nacional. Porque, por añadidura, el discurso regionalista, que insistía tanto en la autonomía municipal como en la regional, aparecía trufado de un ideario anticaciquil, modernizador e incluso democratizador.

El éxito logrado por la Solidaritat Catalana en las elecciones generales de 1907, al obtener 41 de los 44 diputados que se elegían en Cataluña, planteó a los dirigentes de los partidos dinásticos el dilema de si podían continuar despreciando a los catalanistas o debían hacerles partícipes de sus posibles planes de

2 Javier Tusell (1994): Antonio Maura, una biografia política, Madrid, Alianza Editorial, 29. 
reformas. Antonio Maura, ese mismo año de 1907, se inclinó por la opción de pactar con los «solidarios» más moderados al aceptar parte de las iniciativas propuestas por Francesc Cambó, en la discusión y elaboración del proyecto de ley de reforma de la Administración local. Esa actitud posibilista permitirá, años después y tras un complejo proceso de acuerdos tácticos con líderes tanto liberales -Canalejas- como conservadores -Dato-, la creación de la Mancomunidad de Cataluña (abril de 1914), organismo sin apenas poder político -era la suma de las cuatro diputaciones provinciales catalanas- que presidiría el más prestigioso de los dirigentes catalanistas, Enric Prat de la Riba.

A los cuatro meses de la constitución de la Mancomunidad estalló la Gran Guerra y fue precisamente esta nueva coyuntura internacional lo que estimuló a los dirigentes de la Lliga Regionalista a dar un paso más y explicitar su proyecto de reformas para España. A lo largo del año 1915 diferentes políticos catalanistas participaron en una serie de conferencias, a las que asistió lo más representativo del mundo empresarial de Cataluña, relativas a cómo debía aprovecharse la neutralidad española ante el gran conflicto europeo ${ }^{3}$. El propio Cambó, en la conferencia de clausura, señaló con claridad que el principal problema que existía entonces en España radicaba en que el Estado era ineficaz, se había quedado anticuado y no estaba a la altura de las necesidades y que los partidos dinásticos eran incapaces de acometer ellos solos las reformas políticas y administrativas más necesarias.

Fue a partir de esta reflexión sobre la necesidad de aprovechar la oportunidad que les estaba ofreciendo el conflicto europeo como Cambó y Prat elaboraron el manifiesto Per Catalunya i l'Espanya Gran, con el que se presentaron los candidatos de la Lliga Regionalista a las elecciones generales de abril de 1916. Por primera vez los catalanistas conservadores elaboraban un manifiesto dirigido a todos los españoles, llamándoles a participar en la tarea de reformar y modernizar

\footnotetext{
3 Lliga Regionalista (1915): El pensament català davant del conflicte europeu: conferencies dels parlamentaris regionalistes, Barcelona.
} 
la Administración pública española. Poniendo la Mancomunidad como punto de partida generalizable para toda España, los catalanistas de la Lliga defendían la necesidad de ir a la constitución de diversas entidades autonómicas regionales como principal instrumento de la regeneración política de España. Pero, para lograr este objetivo, debían incorporarse a la política activa y a la gestión gubernamental todos los sectores que hasta entonces habían sido marginados del poder por los dinásticos, las llamadas «clases neutras».

Para lanzarse a esta aventura política, el catalanismo conservador tuvo que enfrentarse al dilema, y superarlo, respecto a qué era lo más prioritario en su estrategia, si impulsar la reforma del Estado español o buscar exclusivamente la resolución del pleito catalán. Esta disyuntiva aparece planteada con claridad en una carta del 5 de noviembre de 1916 que Cambó, desde el Congreso de Diputados, envió a Prat:

Podemos adoptar dos posiciones. Primero, actuar meramente como partido nacionalista planteando con carácter grave el pleito de las delegaciones y haciendo cuestión de ello hasta el punto de obtener un Proyecto autonomista si no se nos da satisfacción. Segundo, actuar como hombres de gobierno presentando enmiendas que mejoren y casi alteren por completo el Proyecto del gobierno. Lo más fácil es lo primero. Difícil pero prestigioso lo segundo ${ }^{4}$.

A partir de entonces Cambó, con el asentimiento de Prat, divulgó un discurso político que presentaba como complementarias ambas tareas: en primer lugar, debían convencer a los catalanes de que únicamente desde el Gobierno de España podía conseguirse y consolidarse la autonomía de Cataluña. Es decir, era preciso dejar de ejercer solo de oposición nacionalista para actuar como hombres de Gobierno en Madrid. La segunda tarea implicaba convencer a los españoles, y en especial a los políticos dinásticos, de que sin Cataluña en España no se podía gobernar. Que ellos necesitaban a los catalanistas si pretendían realmente

\footnotetext{
4 Carta de Francesc Cambó a Enric Prat de la Riba del 5 de noviembre de 1916, Fons Prat de la Riba, Arxiu Nacional de Catalunya. Traducida del catalán original.
} 
modernizar el país, ya que la región más dinámica y más europea no podía continuar estando marginada del poder. Debían convencer a los políticos dinásticos de que Cataluña estaba llamada a ser «el Piamonte de España».

El proyecto español de Cambó y de Prat fue construyéndose a medida que encontraba respuestas positivas a sus propuestas y, sobre todo, a causa del prestigio logrado por el primero en la batalla parlamentaria contra las medidas fiscales del ministro Santiago Alba. El intenso debate parlamentario del año 1916 permitió a Cambó conectar, tanto en el Congreso como fuera de él, con diversos sectores reformistas que hasta entonces parecían pasivos o marginados de la vida política. Su vehemente oposición a los nuevos impuestos sobre los beneficios extraordinarios de guerra propuestos por Santiago Alba, que suponían tasas que iban del $25 \%$ al $40 \%$, convirtió a Cambó en el ídolo de los industriales y de los comerciantes del País Vasco, de Asturias, de Cantabria, de Galicia, de Valencia, etc. Su discurso sobre la renovación de la política económica empezó a tener eco entre los dispersos grupos regionalistas de la periferia, los federalistas, los dirigentes de la Comunión Nacionalista Vasca, los reformistas de Melquíades Álvarez, el Centro Andaluz de Blas Infante y los aragonesistas de Manuel Marraco y, como veremos, también despertó simpatías e apoyos en lo que serían las Irmandades da Fala.

El discurso camboniano, además, tenía un marcado carácter anticaciquil y de defensa de una «nueva política» que acabase con el caduco sistema establecido por conservadores y liberales. Por ello estimuló la movilización de grupos regionales y locales notablemente resentidos por los procedimientos empleados por los dinásticos para monopolizar las representaciones y para copar las instituciones locales y provinciales.

Cambó pretendía también aprovecharse de la división interna de los partidos dinásticos, que no lograban tener líderes reconocidos ${ }^{5}$, para acentuar su fractura,

\footnotetext{
5 Los conservadores estaban divididos entre los partidarios de Maura, de Dato y de La Cierva, y los liberales entre los de Romanones, de Alba y de García Prieto.
} 
pactando con unos y marginando a otros. Su objetivo era construir un frente reformista que impusiera una nueva forma de hacer política, acabando de una vez con el turno exclusivo de los partidos dinásticos y abriendo camino hacia una nueva hegemonía económica.

La operación requería un tacticismo complejo, ya que también pretendía incorporar al bloque reformador algunas agrupaciones de clara índole antidinástica, como a los republicanos e incluso al emergente socialismo. Precisamente uno de los problemas más complejos que surgió entonces era evitar la radicalización de los republicanos y de los socialistas, que a finales de 1916 habían organizado una gran campaña de propaganda en favor de los aliados y de la entrada de España en la guerra en la que predominaba un tono claramente antimonárquico. Para los proyectos de amplias alianzas de Cambó era fundamental neutralizar esa campaña proguerra de los republicanos y evitar que el pacto UGT-CNT, formalizado en diciembre de 1916, pusiera en primer plano las reivindicaciones y las protestas de los trabajadores. En febrero de 1917 la caída del zarismo y el inicio de la Revolución rusa auguraban un año de enorme complejidad, ya que este nuevo estímulo exterior podía entorpecer notablemente el proyecto camboniano.

A principios del año 1917 parecía evidente que Francesc Cambó tenía ya la posibilidad de empezar a construir su frente reformista. Un exitoso viaje al País Vasco, donde se entrevistó con Ramón de la Sota y otros dirigentes empresariales y de la Comunión Nacionalista, así lo daba a entender. En un vehemente discurso pronunciado en Bilbao, el 25 de enero, ante lo más granado del empresariado vizcaíno, Cambó sostuvo que su proyecto pretendía ir «hacia una mayor fraternidad entre todos los pueblos de España y hacia la misma grandeza de una España Imperial» ${ }^{6}$. En abril de ese año volvería al País Vasco, pero ahora a San Sebastián, y después visitaría Asturias, Andalucía, Valencia y a final de año, como veremos, Galicia. En todas partes los discursos de Cambó ocupaban las

\footnotetext{
6 Reproducido en La Veu de Catalunya el 26 de enero de 1917.
} 
primeras páginas de los diarios locales y regionales. Se estaba convirtiendo en el ídolo de la España periférica que pretendía asaltar el centro político.

Pero, al mismo tiempo, Francesc Cambó no dejaba de tener contactos políticos con los principales líderes dinásticos para estar al día de sus trifulcas y de sus pretensiones. A principios de 1917, las relaciones de Cambó con Santiago Alba eran mucho más estrechas y amigables de lo que ambos daban a entender en público, donde aparecían como adversarios irreconciliables. Nada más lejos de la realidad, como lo refleja su correspondencia privada ${ }^{7}$. Así, en abril de ese año, tras una reunión con el rey, Alba llegó a proponer a Cambó «la formación de un gobierno de concentración en el que [entrarían] los 5 o 6 más capaces de la política española para ejercer una Dictadura» ${ }^{8}$. Esta es una prueba evidente del extremo tacticismo de ambos políticos, capaces de explorar sin demasiados escrúpulos todas las posibilidades.

\section{LAS ASAMBLEAS DE PARLAMENTARIOS DE BARCELONA DE JULIO DE 1917}

La crisis de junio de 1917 vino a poner en evidencia la profunda erosión del sistema político de la Restauración. Ante la presión de las Juntas Militares, del sindicalismo obrero -que exigía compensaciones laborales- y de los sectores reformistas, una vez más los partidos dinásticos se mostraban incapaces de ofrecer una salida. El recurso real de nombrar presidente del Gobierno al conservador Eduardo Dato, el 11 de junio, fue acompañado, inevitablemente, del cierre de las Cortes - puesto que el Gobierno no las controlaba-, la suspensión de las

\footnotetext{
7 Utilizo especialmente la correspondencia privada de Cambó que se encuentra en el Fons Borràs, de la Biblioteca de Catalunya -correspondencia de entre 1912 y 1922-, y en los fondos Francesc Cambó, Lluís Durán i Ventosa y Enric Prat de la Riba, en el Arxiu Nacional de Catalunya.

8 Se explica en la carta de F. Cambó a J. Ventosa, del 6 de abril de 1917, Fons Borràs, Biblioteca de Catalunya. Traducido del catalán.
} 
garantías constitucionales, la imposición de censura a la prensa y el pasar a gobernar a base de decretos leyes.

Francesc Cambó encabezó la rebelión contra aquel Gobierno que no contaba con el apoyo parlamentario y pretendía actuar de forma autoritaria. Denunció el sesgo ultraconservador e inmovilista que se estaba imponiendo y por ello lanzó la propuesta de convocar a todos los parlamentarios catalanes para sumarse a la causa de ir «o a la renovación normal y pacífica, o a la revolución violenta». La convocatoria de Cambó tuvo un enorme éxito, ya que, pese a la prohibición gubernamental, el 5 de julio se reunieron en Barcelona 59 diputados y senadores elegidos en Cataluña -solo faltaron dos datistas-. De forma unánime, los parlamentarios aprobaron un manifiesto en el que afirmaban que era la voluntad de los catalanes lograr la autonomía dentro de una profunda renovación del sistema político español y, por tal motivo, llamaban a la convocatoria de unas Cortes Constituyentes que implantaran un régimen autonómico regional y municipal en toda España. Asimismo, consideraban justas las reivindicaciones de las Juntas Militares y de los sindicatos y emplazaban al Gobierno del conservador Dato a aceptar sus demandas. Si no lo hacía, convocarían a los parlamentarios de toda España para que, constituidos en asamblea soberana, actuasen como única y legítima fuente de poder.

Ante tal desafío, el Gobierno Dato, que gracias a la censura de prensa pudo impedir un amplio conocimiento de la Asamblea de Barcelona y de sus pretensiones, buscó el apoyo real para negarse radicalmente a las demandas de los asambleístas y recabó, de igual manera, el apoyo de todos los líderes dinásticos. La crisis política era grave, ya que el desafío asambleísta iba acompañado de anuncios de una fuerte presión en la calle por parte de los republicanos y de los sindicatos obreros. La propia Solidaridad Obrera, el portavoz de la CNT, sostenía que debían aprovechar la oportunidad, puesto que en España se estaba "como en Rusia»".

9 Citado por Ángel Smith, op. cit., página 485. 
Pero la segunda Asamblea de Parlamentarios, reunida también en Barcelona el 19 de julio, fue un relativo fracaso, ya que solo estuvieron presentes 68 diputados y senadores, la mayoría antidinásticos. Aunque acudieron los más relevantes dirigentes de la oposición -el republicano Alejandro Lerroux, el socialista Pablo Iglesias y el reformista Melquíades Álvarez-, fue muy notable la ausencia de los líderes dinásticos. Cambó y los catalanistas conservadores eran los únicos moderados en una asamblea en la que predominaban los antimonárquicos. También por unanimidad se aprobó allá un manifiesto dirigido al país en el que se hacía hincapié en la necesidad de realizar profundas reformas y de constituir un nuevo Gobierno que convocase unas Cortes Constituyentes, al tiempo que se insistía en cuestiones más concretas, como una nueva ley electoral y la autonomía regional y municipal.

Pese a que Cambó aparecía como la cabeza visible del movimiento asambleísta, el político catalanista empezaba a dudar de sus posibilidades para controlar el movimiento que él mismo había ideado. Y mucho más tras la radicalización de la situación política provocada por la convocatoria de una huelga general obrera para el mes de agosto. El pacto firmado por la CNT y la UGT contra la vida cara y en favor de los derechos sindicales, y la propia radicalización política de los republicanos y los socialistas, llevaron al convencimiento, a muchos de los dirigentes de las izquierdas, de que aquel era el momento más adecuado para hacer caer al desprestigiado Gobierno Dato y forzar un cambio político. El 13 de agosto se inició precipitadamente una huelga general de los Ferrocarriles del Norte -al parecer provocada por el propio Gobierno y la patronal ferroviariaque desbordó las previsiones de los comités de huelga creados por los republicanos y socialistas. La huelga se extendió sin dirección y sin control y el Gobierno, que logró la fidelidad del Ejército, pudo reprimir violentamente la revuelta obrera -66 muertos en toda España, la mitad de ellos en Barcelona- y acusar a los asambleístas de ser cómplices de los huelguistas y de haber potenciado una revolución violenta. 
El movimiento asambleísta se había roto entre los antimonárquicos, que habían potenciado la huelga general, y los moderados, partidarios de procedimientos pacíficos. Por su parte, las principales organizaciones patronales censuraron con dureza a los asamblearios, y concretamente a Cambó, por sus actuaciones imprudentes y desestabilizadoras. El propio presidente del Fomento del Trabajo Nacional, Josep de Caralt, amenazó con constituir en Cataluña un bloque electoral conservador frente a la Lliga de Cambó.

Ahora bien, como una prueba más de la habilidad política de Francesc Cambó, debe señalarse que este político, ya durante los sucesos de agosto de 1917, mantenía un contacto secreto con Alfonso XIII para mirar de propiciar un cambio de estrategia del movimiento de los asambleístas ${ }^{10}$. Ha de recordarse que el rey estaba teniendo un destacado, e incluso excesivo, protagonismo político desde 1904. Sus poderes eran cruciales en el peculiar sistema de la Constitución de 1876, ya que era él quien designaba y cesaba a los Gobiernos, quien disolvía las Cortes y quien convocaba las elecciones y, además, en uso de su cosoberanía, tenía un veto suspensorio de las leyes, al tiempo que era inviolable. La propia intervención de Alfonso XIII había sido decisiva para dividir el partido conservador entre mauristas y datistas. Una muestra del carácter peculiar del monarca aparece en una entrevista publicada entonces en el Daily Express de Londres, en la que el rey, con poca prudencia, sostenía que él era el político más moderno de España y que la mayoría de los dirigentes dinásticos eran unos incompetentes ${ }^{11}$.

Así, ya en agosto de 1917 hubo contactos discretos entre Alfonso XIII y Cambó y bien pronto fue evidente su coincidencia en que había que evitar la caída de la monarquía. Pero, según Cambó, el precio que habría que pagar era cambiar los criterios en la formación de los Gobiernos, es decir, acabar con el

\footnotetext{
${ }^{10}$ Las gestiones confidenciales entre el rey y Cambó las realizaron especialmente Joan Antoni Güell i López, conde de Güell, el empresario Damià Mateu y, sobre todo, la duquesa de Dúrcal, Leticia Bosch-Labrús, íntima amiga de Cambó y dama de la reina Victoria Eugenia.

${ }^{11}$ Entrevista reproducida por José Gutiérrez-Ravé (1955): Habla el Rey, Madrid, s. n., 151.
} 
turno en el poder de los dos partidos dinásticos. Ambos coincidieron también en que era preciso constituir un Gobierno de amplia coalición con políticos nuevos y prestigiosos, y que ese nuevo Ejecutivo debía plantearse o bien una reforma profunda de la Constitución de 1876, o bien la elaboración de una nueva carta magna. Y que todo ese complejo proceso político tenía que estar firmemente controlado desde el Gobierno para evitar que los desbordasen los antimonárquicos. De la empatía existente entre ambos eran una clara muestra las constantes manifestaciones de adulación del rey, al considerar a Cambó «el único que [podía] salvar la situación» ${ }^{12}$.

\section{LA FALSA SOLUCIÓN DEL GOBIERNO DE CONCENTRACIÓN Y EL FRACASO EN LAS ELECCIONES DE 1918}

Estos acuerdos tácitos fueron preparando el pacto político que se acordó en la entrevista del 30 de octubre de 1917. Cambó sabía que, si deseaba liderar a las nuevas clases medias y a las burguesías reformistas y regionalistas de toda España, no podía tener como aliados a los radicalizados republicanos y a los socialistas. Las cosas evolucionaban con arreglo a los planes de Cambó, puesto que a la segunda fase de la Asamblea de Parlamentarios, ahora reunida en el Ateneo de Madrid a principios de octubre de 1917, ya no asistieron ni los socialistas ni la mayoría de los republicanos. De este modo, la gente de la Lliga, junto con los reformistas de Álvarez, algunos liberales y unos pocos republicanos, pudieron proseguir con sus propuestas reformadoras, bajo la clara inspiración de Cambó. Eso quedó patente en la primera declaración pública de la Asamblea, tras los sucesos de agosto, en la que se sostenía que debía evitarse ir a «una revolución desde abajo que [podía] conducir a situaciones como la de Rusia» ${ }^{13}$.

\footnotetext{
${ }^{12}$ Carta de Damià Mateu a Francesc Cambó, del 20 de octubre de 1917.

${ }^{13}$ Nota reproducida en la La Veu de Catalunya, 10 de octubre de 1917.
} 
En las reuniones de los asambleístas en Madrid, por consejo de Cambó, se elaboró un programa con las reivindicaciones máximas, para tener así más margen de maniobra a la hora de negociar con los dirigentes dinásticos. Por ello, incluyeron en su proyecto constitucional la necesidad de privar al rey de la condición de cosoberano y de que la soberanía residiese exclusivamente en las Cortes, y de que desaparecieran los senadores designados, los vitalicios y el veto real de suspensión de las leyes. De igual manera, se hacía hincapié en la necesidad de una profunda reforma de todas las Administraciones públicas, la central y la municipal, y la creación de las nuevas regionales, así como en la elaboración de una nueva ley electoral más representativa y democrática. Cambó quería jugar fuerte y estaba convencido de que incluso podían advertir al rey de que no estaba en condiciones de despreciar la fuerza del catalanismo ${ }^{14}$.

Tras la entrevista entre el monarca y Cambó del 30 de octubre, todo parecía pactado. El rey ofreció la presidencia del Gobierno al liberal José García Prieto, yerno del viejo Montero Ríos, pero a condición de que incluyese en el gabinete a dos asambleístas y a políticos dinásticos de todas las fracciones. Era el primer Gobierno de "concentración», es decir, de coalición, en la historia del régimen de la Restauración. Los asambleístas designados como ministros fueron el lliguero Joan Ventosa i Calvell -el brazo derecho de Cambó- y el hasta entonces reformista Felip Rodés, un abogado catalán que pronto se convertiría en compañero de viaje de los catalanistas conservadores. El resto del gabinete estaba integrado por siete dinásticos de los que tan solo destacaba el viejo cacique conservador Juan de la Cierva.

Cambó estaba eufórico; consideraba que el nuevo Gobierno iniciaba una nueva era en la política del régimen de la Restauración y estaba convencido de que las futuras Cortes serían auténticamente representativas, ya que habría unas elecciones limpias y no manipuladas por el Ministerio de Gobernación. Era tan grande su entusiasmo que incluso se veía presidente del próximo Gobierno,

${ }^{14}$ Véase Rafael de Marquina (1926): La nostra gent: Francesc Cambó, Barcelona, Llibreria Catalònia, 52-53. 
gracias a poder contar en las futuras Cortes con un mínimo de 150 diputados adictos a su persona y a su programa reformador. Y por ello no escatimaba sus elogios al rey por su valentía al romper con el sistema del turno ${ }^{15}$.

Pero esta actitud optimista duró bien poco. Pronto empezó a surgir en él la preocupación de si no había sido demasiado ingenuo al confiar excesivamente en los políticos dinásticos. Tanto Cambó como los ministros Ventosa y Rodés empezaron a darse cuenta de que el presidente del Gobierno, García Prieto, no se imponía a las fracciones dinásticas y dejaba que estas actuaran libremente para evitar perder sus influencias en la mayoría de los distritos electorales, sobre todo en los rurales, y de que las elecciones podían ser menos limpias de lo previsto y deseado ${ }^{16}$.

Ante la elecciones generales del 24 de febrero de 1918, la Lliga Regionalista redactó el manifiesto de los asambleístas y reformistas españoles, que se titulaba Por la España Grande, en el que se insistía en lo decisivos que serían aquellos comicios para poder empezar una nueva era en la política española. Pero, para construir aquella amplia alianza de reformistas, Cambó tuvo que llevar a cabo una serie de pactos electorales, bastante complejos y variados. Así, en Cataluña, la Lliga llegó a acuerdos con exliberales y exmauristas, con carlistas, con reformistas y con algunos republicanos, pero en Barcelona se enfrentó a la candidatura del Frente de Izquierdas, integrada por los republicanos -Lerroux, Domingo- y los socialistas -Largo Caballero-. Es decir, la derecha y la izquierda de la primera Asamblea de Parlamentarios, la de julio de 1917, aparecían ahora enfrentadas en opciones rivales.

En el resto de España, Cambó, con lo que quedaba de los asamblearios, fue tejiendo diferentes pactos electorales adaptándose a las peculiaridades de cada

\footnotetext{
${ }^{15}$ Cartas de Francesc Cambó a Lluís Duran i Ventosa, del 20 de octubre y del 5 de noviembre de 1917, Fons Duran i Ventosa, Arxiu Nacional de Catalunya, y de Francesc Cambó a Joan Ventosa i Calvell, del 6 de noviembre de 1917, Fons Borràs, Biblioteca de Catalunya.

${ }^{16}$ Carta de Francesc Cambó a Joan Ventosa del 14 y el 18 de enero de 1918, Fons Borràs, Biblioteca de Catalunya.
} 
zona. Eran unos acuerdos dispares e incluso difíciles de concretar, ya que, como la mayoría de los distritos eran unipersonales, debían designar a solo un candidato que se enfrentaría al de los caciques dinásticos. Por ello, los pactos electorales fueron notablemente diversos, puesto que participaban en ellos fuerzas heterogéneas. En el País Vasco, los representantes del proyecto reformador de Cambó eran básicamente los candidatos de la Comunión Nacionalista Vasca y algunos independientes. En Asturias lo eran los de la Junta Regionalista Asturiana y los reformistas de Melquíades Álvarez. En Valencia era la gente de la Unión Valencianista, dirigida por el empresario Ignacio Vilallonga; en las Baleares, los regionalistas del Centre Mallorquinista; en Andalucía era el Centro Andaluz, que lideraba el notario Blas Infante; y en Galicia, como veremos con más detenimiento, los acuerdos incluyeron a las Irmandades da Fala, los agraristas y algunos republicanos y mauristas.

Durante la larga campaña electoral, que duró de diciembre de 1917 a febrero de 1918, Francesc Cambó realizó diversos viajes de propaganda por el País Vasco, Galicia, Andalucía -Sevilla y Córdoba- y Valencia. Sin embargo, ya en enero de 1918 empezó a ser consciente de que estaba siendo engañado por los dinásticos y de que el propio presidente, García Prieto, les estaba «tomando el pelo». Temía que las elecciones reflejaran la debilidad política de los asambleístas y reformistas y que los dos ministros asamblearios hicieran el ridículo. Ventosa y Rodés eran rehenes de un Gobierno que no controlaban y tendrían que responsabilizarse de los previsibles malos resultados electorales. Ante la convicción de ir hacia un fracaso seguro, Cambó señalaba como culpables tanto la deslealtad de los dinásticos como su propia ingenuidad ${ }^{17}$.

El 6 de febrero, 18 días antes de las elecciones, ante la seguridad de su fracaso electoral, Cambó no dudó en especular sobre una insólita propuesta autoritaria: participar en un golpe de Estado protagonizado por el propio rey, los

${ }^{17}$ Carta de Francesc Cambó a Joan Ventosa, del 6 de febrero de 1918. Fons Borràs, Biblioteca de Catalunya. 
militares y los políticos nuevos ${ }^{18}$. La persistencia de estas especulaciones sobre posibles salidas dictatoriales refleja, entre otras cosas, que las convicciones democráticas de él, y de la mayoría de los políticos dinásticos, eran muy débiles y que con facilidad podían ceder ante las tentaciones autoritarias.

Las elecciones de 24 de febrero de 1918 significaron, en efecto, un notable fracaso para las aspiraciones de Cambó y de su frente reformista. Los 150 diputados soñados tres meses antes se convirtieron en tan solo 32, y de ellos la mayoría, 21, habían sido elegidos en Cataluña. Fuera de allí, únicamente en el País Vasco la operación reformista parecía haberse impuesto, al lograr los nacionalistas la elección de siete diputados. En el resto de España los resultados eran muy pobres: dos diputados en Asturias, uno en Galicia y uno en Castilla. Frente a ellos, los dinásticos seguían controlando en Congreso, a pesar de estar notablemente divididos en diferentes fracciones. Los liberales tenían 164 diputados y los conservadores 155; es decir, en conjunto, los dinásticos disponían de una clara mayoría parlamentaria, con 319 representantes. Frente a ellos, las diferentes formaciones reformistas o antimonárquicas poca cosa podían hacer: 15 republicanos, 6 socialistas, 8 reformistas, 7 nacionalistas vascos, 12 independientes y los 21 del bloque camboniano catalán. En total eran tan solo unos 70 los diputados que propiciaban importantes cambios políticos en España.

\section{LAS RELACIONES DE FRANCESC CAMBÓ CON LOS GALLEGUISTAS}

Francesc Cambó visitó Galicia en septiembre de 1917, dos meses antes de la formación del Gobierno de concentración de García Prieto. Aunque no otorgaba

\footnotetext{
18 «Fracasado el intento, perfectamente constitucional, encarnado en la solución dada a la crisis del 30 de octubre, yo no veo más solución a la crisis de la política española que un golpe de Estado: que un gobierno, apoyado en el Rey y en las bayonetas, haga lo que no podrá hacer el Parlamento [...]». Carta de Francesc Cambó a Joan Ventosa, del 6 de febrero de 1918. Fons Borràs, Biblioteca de Catalunya. Traducido del catalán.
} 
a este país la importancia política que atribuía al País Vasco, consideraba que era importante su presencia allí para establecer contactos de cara a futuras alianzas. Estuvo en La Coruña, donde se reunió con los más destacados dirigentes de las Irmandades da Fala, Antón Villar Ponte, Rodrigo Sanz y Luís Porteiro. Dos meses más tarde, estos tres políticos galleguistas se trasladaron a Barcelona para participar en la Semana Galega y en una serie de actos organizados por diversas entidades catalanistas en favor de la autonomía gallega ${ }^{19}$. El resultado de los acuerdos tomados entonces en Barcelona fue un segundo viaje de Cambó y otros políticos catalanistas a Galicia a mediados de diciembre de 1917, al inicio de la campaña electoral. Los delegados catalanistas visitaron entonces La Coruña, Santiago, Lugo, Vigo, Orense y Monforte, donde pronunciaron diversas conferencias y se entrevistaron con diferentes políticos. En el curso de esta segunda estancia en Galicia, Cambó pudo detectar las tensiones existentes entre los diferentes grupos a los que deseaba integrar en su frente reformista y autonomista. En efecto, las relaciones entre los dirigentes de las Irmandades con los agraristas, los tradicionalistas y los mauristas no resultaban nada cordiales. Unos eran ultracatólicos y otros notablemente laicos; unos claramente monárquicos y otros más bien republicanos o indiferentes; unos defendían un inconcreto regionalismo y otros eran ardientes partidarios de la autonomía política de Galicia.

Finalmente, Cambó fue aceptado por todos como su líder español, y el político catalanista delegó sus poderes en Galicia en Rodrigo Sanz y Luís Porteiro. La operación política y electoral iba acompañada de la compra del diario $E l$ Noroeste para poder disponer de un importante portavoz en Galicia ${ }^{20}$. Sin embargo, pronto surgieron diversos problemas políticos. Al primero, derivado

\footnotetext{
${ }^{19}$ En el Centre Autonomista de Dependents del Comerç i de la Indústria (CADCI), de Barcelona, se pronunciaron cuatro conferencias: sobre la lengua gallega, la situación política, la cuestión agraria y el derecho civil y la cuestión foral. También participó en los actos Aurelio Ribalta y entonces se constituyó en Barcelona la Comissió Catalana pro-homenatge a Rosalía de Castro.

${ }^{20}$ La compra de diario costó 160000 pesetas, cantidad muy respetable. Cambó impuso al periodista catalanista Pere Muntañola como su director. Muntañola era un íntimo colaborador de Prat de la Riba.
} 
del total control ejercido desde Barcelona del proceso de pactos y alianzas electorales, se sumaron las tensiones provocadas precisamente por la designación de los candidatos para los diferentes distritos gallegos. Gracias a la presión ejercida desde Barcelona, se impusieron los candidatos propuestos por los agraristas y los mauristas, en perjuicio de los galleguistas, que pronto manifestaron su malestar con actos y escritos de protesta. Al final solo había cuatro candidatos de las Irmandades, frente al claro predominio de agraristas, mauristas e incluso republicanos. Además, la fragilidad de la alianza se vio reflejada en la persistencia de la controversia ideológica sobre si el frente reformista encabezado por Francesc Cambó no sería excesivamente «industrialista» y, por ello, no dejaría de defender a fondo los intereses del agrarismo gallego.

En Galicia, el fracaso de la operación reformista-autonomista en las elecciones del 24 de febrero fue casi total. Solo se logró la elección del joven político maurista José Calvo Sotelo por el distrito de Orense. La maquinaria caciquil había actuado con eficacia y, con el apoyo de los gobernadores civiles, habían logrado que fueran elegidos los candidatos de siempre, los fieles a los caciques dinásticos.

Este fracaso fue seguido de la retirada gradual de la ayuda económica de los catalanistas conservadores a las Irmandades da Fala, hecho que acabó provocando la radicalización de buena parte del galleguismo. Empezaron a surgir entonces las dudas sobre si la vía reformista y pacífica de Cambó era la más adecuada para llegar a la autonomía o si se debía cuestionar la Constitución y la propia monarquía. El fracaso electoral había incrementado las desconfianzas y las críticas al propio Cambó, notablemente a partir de la entrada de este, en marzo de 1918, en el Gobierno Nacional presidido por Antonio Maura.

Los galleguistas de las Irmandades se iban orientando cada vez más hacia los valores democráticos y sociales de las izquierdas y se distanciaban del pragmatismo camboniano, con el que solo coincidían en la cuestión autonomista. Fue entonces, ante un Cambó ministro de Fomento de un Gobierno integrado por todos los líderes dinásticos, cuando proliferaron las censuras al "plutócrata» 
catalanista por parte de los galleguistas más vehementes. Vicente Risco le calificó de «roñoso judío» y de ser un político nefasto para el galleguismo. Por ello, cuando en 1919 y 1923 Cambó intentó tímidamente repetir la experiencia de las alianzas de 1918, en Galicia apenas encontró aliados. El galleguismo había roto sus relaciones con la Lliga Regionalista y con Cambó, y a este solo le quedaban como principales contactos políticos en Galicia personas como Manuel Portela Valladares ${ }^{21}$.

\section{EL FRACASO DE LA OPERACIÓN REFORMISTA Y REGIONALISTA DE 1917-1918}

Francesc Cambó sobrevaloró las posibilidades que tenía el régimen de la Restauración para ser transformado y renovado desde dentro. Primero intentó desestabilizarlo para forzar un cambio, utilizando la fuerza política de las primeras Asambleas de Parlamentarios, las julio de 1917. Pero se equivocó porque los partidos dinásticos pudieron resistir entonces el desafío. Después, cuando estos aceptaron integrarle en el sistema, con la formación del Gobierno de concentración de García Prieto, fueron mucho más hábiles que él y le «tomaron el pelo». Las elecciones de febrero de 1918, en las que Cambó había depositado tantas esperanzas, y tantos esfuerzos, fueron ganadas por los dinásticos porque utilizaron sin reparos los procedimientos tramposos de siempre. Tanto el Ministerio de la Gobernación como los gobiernos civiles y los alcaldes dinásticos mostraron que no estaban dispuestos a tolerar la democratización del voto, ya que su principal fuente de poder residía precisamente en el control político de la mayoría de los distritos rurales y de no pocas ciudades medias.

\footnotetext{
${ }^{21}$ Sobre las relaciones entre las Irmandades y los catalanistas de Cambó, véase especialmente el capítulo «A alianza co catalanismo e as eleccións de febreiro de 1918», en el libro de Justo Beramendi (2007) De provincia a nación: historia do galeguismo político, Vigo, Edicións Xerais de Galicia, 452-467.
} 
Las Cortes seguirían siendo dominadas por los contrarios al proceso constituyente, o a la reforma de la Constitución de 1876, que eran los que también se oponían a la regionalización de España y a la implantación de un régimen de autonomías. Los reformadores eran una minoría impotente, incapaz de forjar un cambio político de relevancia.

El propio Cambó pudo comprobar poco después, siendo ya ministro de Fomento en el Gobierno Nacional de Maura (marzo-noviembre de 1918), los límites de su acción transformadora. Se sentía un rehén de los ministros dinásticos, que boicoteaban toda propuesta suya que fuera más allá de lo que ellos podían tolerar, como después también sucedería con el fracaso del proyecto de estatuto de autonomía catalán, el presentado en las Cortes en noviembre de ese mismo 1918.

Tanto el Gobierno de concentración de García Prieto como el Nacional de Maura eran una falsa solución a los muchos y graves problemas que tenía planteados el país. El propio carácter de sus miembros, la mayoría veteranos políticos dinásticos, no permitía ni abordar seriamente una discusión política sobre el carácter de las transformaciones que debían hacerse. En esos Gobiernos era imposible debatir sobre las reformas administrativas, sobre la democratización de los procesos electorales ni sobre cómo podían atenderse las necesidades sociales, ni menos aún sobre cómo avanzar hacia una nueva Constitución.

La compleja operación reformista de Francesc Cambó tenía, desde el principio, pocas posibilidades de triunfar. Era una alianza muy heterogénea de fuerzas reformistas que solo podía lograr algún éxito si una parte significativa de los dinásticos se sumaba a ella, o se avenía a pactar algunas reformas. Pero, ante el gran desafío que supuso la huelga general de agosto de 1917, potenciada por los antimonárquicos, la totalidad de las fracciones dinásticas se replegaron para defender su sistema político. Eran unas formaciones que tenían mucho que perder, y poco que ganar, si se pretendía cambiar radicalmente la situación política española. Por ello, solo algunos dirigentes, como Santiago Alba, y con no pocas dudas, estaban dispuestos a tratar la cuestión de las reformas, pero sin presiones ni amenazas. 
Desde agosto de 1917 era evidente que la izquierda asambleísta era antimonárquica y que quería ir más lejos, hacia una república, como en Portugal. Pero no tenían la fuerza ni la organización, ni podía contar con el Ejército, como se vio claramente con la dura represión de la huelga de agosto. Fue entonces cuando las dudas de Cambó ante las pretensiones de estos indeseados aliados se desvanecieron. No podía seguir más tiempo con ellos y debía pactar con los poderes auténticos, con el rey y con los líderes de los partidos dinásticos, para ver si el sistema se abría un poco y se podía potenciar alguna reforma «desde dentro».

Otro de los efectos provocados por la operación reformista encabezada por Francesc Cambó fue el surgimiento de una nueva derecha autoritaria y nacionalista española, vehementemente opuesta a todos los proyectos autonomistas y al protagonismo de los catalanistas. En 1919 había nacido en Barcelona, como clara opción palaciega, la Unión Monárquica Nacional, un grupo notablemente anticatalanista y antirrevolucionario en el que confluían políticos dinásticos, líderes patronales, aristócratas y el «partido militar» que en la Capitanía General de Cataluña y en el Gobierno Civil de Barcelona estaban creando los generales Milans del Bosch y Martínez Anido.

Entre 1918 y 1923, once Gobiernos, de diversa composición, pero todos ellos presididos por políticos dinásticos, se sucedieron en España sin que ninguno de ellos lograse impulsar reformas mínimamente efectivas. El régimen de la Restauración se resistía a todo cambio político profundo y fue erosionándose hasta el golpe militar de septiembre de 1923. Sin embargo, el recurso a la dictadura militar acabó por desprestigiar notablemente al rey y a la misma institución monárquica. Luego, en 1930, los políticos dinásticos fueron incapaces de aprovechar la etapa provisional del Gobierno Berenguer para ofrecer una posibilidad sincera de cambio constitucional. El propio Francesc Cambó, que había esperado el fin de la dictadura porque entonces llegaría su hora, no tuvo entonces el coraje del año 1917 y consideró que la dictadura había sido un paréntesis y que podía regresarse sin problemas al normal funcionamiento del régimen de la Restauración. En abril de 1931 comprobaría su grave error. Había minusvalorado 
el desprestigio de la monarquía y la fuerza del movimiento republicano, y se encontró que unas elecciones municipales se habían convertido en un plebiscito popular inapelable. Así, el 14 de abril se produjo una coincidencia casi sarcástica en Madrid: mientras Alfonso de Borbón marchaba hacia Cartagena para embarcarse rumbo a Francia, a la misma hora Francesc Cambó subía al Sud-Express que le llevaría a París. Ambos salían de España como unos políticos derrotados por el voto popular. Ahora sí que empezaban las reformas de verdad. 